\title{
Practical approach to management of chronic lymphocytic leukemia
}

\author{
Lukáš Smolej, Martin Šimkovič
}

$4^{\text {th }}$ Department of Internal Medicine - Hematology, University Hospital Hradec Králové and Charles University in Prague, Faculty of Medicine in Hradec Králové, Czech Republic

\author{
Submitted: 27 August 2014 \\ Accepted: 11 October 2014
}

Arch Med Sci 2016; 12, 2: 448-456

DOI: 10.5114 /aoms.2016.55424

Copyright @ 2016 Termedia \& Banach

\section{Abstract}

Revolutionary progress has recently changed the landscape of chronic lymphocytic leukemia (CLL). Powerful prognostic factors, especially p53 mutation and/or deletion and IGHV mutation status, have refined individual patient prognosis. Purine analogs and monoclonal antibodies paved the way from palliative treatment to chemoimmunotherapy capable of eradication of minimal residual disease and prolongation of survival. Obinutuzumab (GA-101) and ofatumumab have been recently approved for the treatment of comorbid patients. Bendamustine is available for first-line treatment of patients ineligible for fludarabine, cyclophosphamide, and rituximab (FCR). High-dose glucocorticoids combined with rituximab represent a promising option for refractory CLL; ofatumumab is approved for fludarabine- and alemtuzumab-refractory patients. Allogeneic stem cell transplantation is the only curative option but is feasible in a highly selected group of patients only. The novel small molecule inhibitors ibrutinib and idelalisib have been recently approved for relapsed/refractory CLL. This review provides practical advice for diagnosis, prognostication and treatment of CLL.

Key words: drug therapy, ibrutinib, idelalisib, leukemia, lymphocytic, chronic, obinutuzumab, ofatumumab, prognosis.

\section{Introduction}

Chronic lymphocytic leukemia (CLL) is the most common adult leukemic disorder in the Euro-American population [1]. Recent years have brought several breakthroughs in prognostic assessment and the therapeutic approach. Indeed, mutation and/or deletion of p53 and immunoglobulin heavy chain variable region (IGHV) mutation status emerged as the most powerful markers which greatly improved evaluation of the individual patient's prognosis [2, 3]. With regard to treatment, the fludarabine, cyclophosphamide, and rituximab regimen (FCR) is considered the gold standard in treatment of physically fit CLL patients in first-line therapy as well as after relapse [4,5]. Furthermore, several more therapeutic options are currently at hand for the first-line or relapsed/refractory setting, e.g., bendamustine, alemtuzumab, ofatumumab, or high-dose corticosteroids [6-9]. Allogeneic stem cell transplantation, the only curative treatment option in CLL, is currently almost exclusively performed using reduced-intensity conditioning. This, together with better supportive care, leads to a significant decrease in transplant-related morbidity and mortality $[10,11]$. Finally, many new promising molecules such as ibru-

\author{
Corresponding author: \\ Lukáš Smolej \\ $4^{\text {th }}$ Department of Internal \\ Medicine - Hematology \\ University Hospital Hradec \\ Králové and Charles \\ University in Prague \\ Faculty of Medicine \\ in Hradec Králové \\ Czech Republic \\ 581 Sokolská St \\ 50005 Hradec Kralove, \\ Czech Republic \\ Phone: +42 0776704987 \\ E-mail: lukas.smolej@fnhk.cz
}


tinib, idelalisib, and obinutuzumab are currently undergoing testing within clinical trials [12]. This article covers the practical aspects of diagnosis, prognostication, and treatment of CLL.

\section{Diagnosis and initial work-up}

Chronic lymphocytic leukemia is nowadays diagnosed most frequently in asymptomatic patients when leukocytosis with lymphocytosis is accidentally found in the blood count performed within routine check-ups by a general practitioner or before a scheduled operation. In contrast to other indolent lymphoproliferative disorders, diagnosis of CLL is based on examination of peripheral blood by complete blood count and flow cytometry [13] (Table I). Chronic lymphocytic leukemia typically shows a highly distinctive immunophenotype with positivity for CD5, CD19 and CD23. The flow cytometric diagnostic score for CLL [14] is very helpful for differential diagnosis (Table II). Neither bone marrow aspiration/biopsy nor lymph node biopsy is required for the diagnosis of CLL and should be performed only in case of diagnostic ambiguity. Initial work-up should comprise patient's history, physical examination (including liver, spleen and lymph node palpation and performance status) and basic laboratory tests (complete blood count, biochemistry including electrolytes, renal functions, liver tests, lactate dehydrogenase, and protein electrophoresis, direct antiglobulin test, serum immunoglobulins) as recommended by International Workshop on CLL (IWCLL) 2008 guidelines [13]. In addition, it seems beneficial to use abdominal ultrasonography to detect possible retroperitoneal lymphadenopathy as it detects lymph nodes otherwise inaccessible to physical examination; presence of abdominal lymphadenopathy is associated with shorter time to treatment $[15,16]$.

\section{Prognostic evaluation}

Clinical staging systems by Rai et al. [17] and Binet et al. [18] serve as the basis for assessment of prognosis in CLL (Tables III and IV). They are based on simple and widely available methods (physical examination, complete blood count). However, these systems cannot identify patients diagnosed in early stages (currently the majority of patients) who will rapidly progress and have an unfavorable prognosis. Therefore, further refinement of individual prognosis requires more detailed laboratory assessment. Many prognostic markers have been discovered since the 1990s but only a few are recommended in routine practice. Traditional prognostic parameters recommended for initial evaluation include lymphocyte doubling time and serum $\beta_{2}$-microglobulin or thymidine kinase [13]. With regard to newer parameters, cytogenetic aberrations detected by fluorescent in situ hybridization
(FISH) are currently considered the most useful for clinical practice. In particular, 17p deletion [19-21] and/or p53 mutation [22] are the most powerful factors conferring rapid progression, low sensitivity to treatment and short overall survival [23]. Therefore, these two tests are desirable at least before initiation of first-line treatment; in addition, repeated testing before subsequent lines of treat-

Table I. Diagnostic criteria for chronic lymphocytic leukemia (CLL)

\begin{tabular}{|l|}
\hline 1. B-lymphocytes in peripheral blood $>5 \times 10^{9} / 1$ \\
\hline $\begin{array}{l}\text { 2. Less than } 55 \% \text { atypical lymphocytes } \\
\text { (e.g., prolymphocytes) in peripheral blood }\end{array}$ \\
\hline 3. Typical immunophenotype \\
\hline
\end{tabular}

Table II. Flow cytometry score for chronic lymphocytic leukemia (CLL) diagnosis. slg - surface immunoglobulin. Chronic lymphocytic leukemia cases typically have a score of 4-5; other indolent lymphomas usually have a score of $0-2$

\begin{tabular}{|lcc|}
\hline Marker & \multicolumn{2}{c|}{ Points } \\
\cline { 2 - 3 } & 1 & 0 \\
\hline CD5 & Positive & Negative \\
\hline CD23 & Positive & Negative \\
\hline slg & Weak & Strong \\
\hline CD79b & Weak & Strong \\
\hline FMC7 & Negative & Positive \\
\hline
\end{tabular}

Table III. Rai staging. Modified three-stage system (1987) assigns low risk to stage 0 , intermediate risk to stage I/II and high risk to stage III/IV

\begin{tabular}{|lc|}
\hline Stage & Definition \\
\hline 0 & Lymphocytosis \\
\hline I & Lymphadenopathy \\
\hline II & Hepatomegaly and/or splenomegaly \\
\hline III & Anemia, hemoglobin $<110 \mathrm{~g} / \mathrm{I}$ \\
\hline IV & Thrombocytopenia $<100 \times 10^{9} / /$ \\
\hline
\end{tabular}

Table IV. Binet staging. Cervical, axillary, inguinal lymph nodes, liver and spleen are each counted as one area. Bilateral involvement is counted as one area

\begin{tabular}{|lc|}
\hline Stage & Definition \\
\hline A & $<3$ involved areas \\
\hline B & $\geq 3$ involved areas \\
\hline C & $\begin{array}{r}\text { Anemia (hemoglobin }<100 \mathrm{~g} / \mathrm{l}) \\
\text { and/or thrombocytopenia }<100 \times 10^{9} / \mathrm{l}\end{array}$ \\
\hline
\end{tabular}


Table V. International Workshop on CLL (IWCLL) indication criteria for treatment

\begin{tabular}{|l|}
\hline 1. Progressive bone marrow failure: development and/or worsening of anemia and/or thrombocytopenia \\
\hline 2. Massive ( $>6 \mathrm{~cm}$ below left costal margin) or progressive/symptomatic splenomegaly \\
\hline 3. Massive ( $>10 \mathrm{~cm}$ in largest diameter) or progressive/symptomatic lymphadenopathy \\
\hline 4. Progressive lymphocytosis with increase $>50 \%$ in 2 months or lymphocyte doubling time $<6$ months \\
\hline 5. Autoimmune anemia and/or thrombocytopenia poorly responding to corticosteroids or other standard treatment \\
\hline $\begin{array}{l}\text { 6. Systemic symptoms associated with CLL: } \\
\text { - weight loss } \geq 10 \% \text { in } 6 \text { months } \\
\text { - significant fatigue (ECOG performance status } \geq 2 \text {, inability to work or to perform everyday activities) } \\
\text { - fevers }>38.0^{\circ} \mathrm{C} \text { for } \geq 2 \text { weeks without evidence of infection }\end{array}$ \\
\hline
\end{tabular}

ment is recommended as patients with CLL may develop clonal evolution [24]. An unmutated sequence for the immunoglobulin heavy chain variable region (IGHV) is also an independent predictor of shorter time to progression and overall survival; however, it is currently not recommended for widespread routine testing [13]. Other parameters such as CD38 or ZAP-70 expression are currently recommended for clinical trials only. Recent studies suggest that novel mutations such as NOTCH1, SF3B1, and BIRC3 also have significant prognostic implications [25-27], but it is too early to incorporate them into routine use.

\section{Indication for treatment}

It is widely accepted that treatment of CLL should only be initiated in the case of disease activity (Table V) [13]. Treatment is therefore usually indicated for advanced clinical stages (Rai III/IV or Binet C). Short lymphocyte doubling time should not be the only reason to initiate treatment in patients with mild leukocytosis $\left(<30 \times 10^{9} / \mathrm{l}\right)$. Other factors contributing to lymphocytosis or lymphadenopathy, especially infections, should be ruled out before commencing treatment. Importantly, though CLL patients may develop an extremely high lymphocyte count, the absolute number of lymphocytes itself is not an indication for treatment because leukostasis is very rare in CLL [13].

\section{Pretherapeutic assessment}

Routine evaluation before commencement of treatment should include physical examination with assessment of organomegaly, performance status, complete blood count, biochemistry, serum immunoglobulins, and direct antiglobulin test [13]. Determination of infection status, especially viral hepatitis A (anti-HAV antibodies IgG and IgM), $B$ (HBs antigen, anti-HBC total and IgM), and C (anti$\mathrm{HCV}$ ), is also very important [13]. As mentioned before, FISH testing for del 17p, del 11q, del $13 q$ and trisomy 12 and analysis of p53 mutations are highly desirable. Patients with anemia and/or thrombo- cytopenia should undergo bone marrow aspirate/ biopsy. Use of imaging methods (e.g. computed tomography - CT) to assess abdominal lymphadenopathy is not generally recommended; however, it may refine pretherapeutic staging as well as evaluation of therapeutic response; abdominal ultrasonography is a cheap and readily available (though less sensitive) alternative to $\mathrm{CT}[13,28]$. Chest radiograph is recommended if $\mathrm{CT}$ is not performed [13].

Chronic lymphocytic leukemia is mainly a disease of the elderly with median age at diagnosis between 65 and 72 years [29-32]. Therefore, it is very useful to assess patient's fitness and general condition and adjust the extent of diagnostic procedures and therapeutic goals accordingly. Biological age is far more useful than simple calendar age. Eastern Cooperative Oncology Group (ECOG) performance status is a suitable basic tool. Ideally, patients should be evaluated for functional capacity and comorbid conditions. One of the possibilities is the Cumulative Illness Rating Scale (CIRS) established by the German CLL Study Group [33]. This system assesses number and severity of comorbidities in each of 13 organ systems. Patients with a cumulative CIRS score $\geq 7$ are considered significantly comorbid. Assessment of renal function using creatinine clearance (most frequently calculated from serum creatinine using the Cockcroft-Gault formula) [34] is very useful as most cytotoxic drugs (e.g. fludarabine, cyclophosphamide, chlorambucil a.o.) are excreted via kidneys and renal impairment is associated with increased hematological and infectious toxicity. Patients up to 70 (possibly 75) years of age with performance status $0-1$, CIRS score $\leq 6$, creatinine clearance $\geq 70 \mathrm{ml} / \mathrm{min}$ and no severe comorbidities (e.g., advanced cardiac failure, ischemic heart disease or chronic obstructive lung disease) represent ideal candidates for intensive treatment such as FCR.

\section{Assessment of therapeutic response}

Therapeutic response should be evaluated according to International Workshop on CLL (IWCLL) 
Table VI. International Workshop on CLL (IWCLL) criteria for therapeutic response

\begin{tabular}{|c|c|c|c|}
\hline Parameter & Complete response (CR) & Partial response (PR) & Progressive disease (PD) \\
\hline \multicolumn{4}{|l|}{ Group A (tumor burden): } \\
\hline Lymphadenopathy & $<1.5 \mathrm{~cm}$ & $\downarrow$ by $\geq 50 \%$ & $\uparrow$ by $\geq 50 \%$ \\
\hline Hepatomegaly & None & $\downarrow$ by $\geq 50 \%$ & $\uparrow$ by $\geq 50 \%$ \\
\hline Splenomegaly & None & $\downarrow$ by $\geq 50 \%$ & $\uparrow$ by $\geq 50 \%$ \\
\hline ALC & $<4 \times 10^{9} / 1$ & $\downarrow$ by $\geq 50 \%$ & $\uparrow$ by $\geq 50 \%$ \\
\hline Bone marrow & $\begin{array}{c}\text { Normocellular, } \\
<30 \% \text { lymphocytes, } \\
\text { no B-cell infiltrates }\end{array}$ & $\begin{array}{c}\downarrow \text { infiltration by } \geq 50 \% \\
\text { or B-cell infiltrates }\end{array}$ & \\
\hline \multicolumn{4}{|l|}{ Group B (hematopoiesis): } \\
\hline Platelets & $>100 \times 10^{9} / 1$ & $\begin{array}{l}>100 \times 10^{9} / 1 \\
\text { or } \uparrow \text { by } \geq 50 \%\end{array}$ & $\uparrow$ by $\geq 50 \%$ \\
\hline Hemoglobin & $>110 \mathrm{~g} / \mathrm{l}$ & $\begin{array}{c}>110 \mathrm{~g} / \mathrm{l} \\
\text { or } \uparrow \text { by } \geq 50 \%\end{array}$ & $\downarrow$ by $\geq 20 \mathrm{~g} / \mathrm{l}$ \\
\hline ANC & $>1.5 \times 10^{9} / 1$ & $\begin{array}{c}>1.5 \times 10^{9} / 1 \\
\text { or } \uparrow \text { by } \geq 50 \%\end{array}$ & \\
\hline
\end{tabular}

CR: All criteria $A$ and $B$ have to be met; patient has no clinical symptoms. PR: At least 2 criteria $A$ and 1 of criteria $B$ have to be met for duration of $\geq 2$ months. PD: Any of the A or B criteria have to be met. Stable disease (SD): neither PR nor PD criteria are met. ANC - absolute neutrophil count, $A L C$ - absolute lymphocyte count, $\mathrm{Hb}$ - hemoglobin.

2008 guidelines (Table VI) [13]. Achievement of a complete or partial response is considered beneficial for the patient. In the case of stable disease or progression, a subsequent line of therapy should be initiated.

\section{Choice of specific treatment regimen}

It is highly recommended to enroll CLL patients in clinical trials whenever possible as this is the only way to further improve therapeutic efficacy.

\section{First-line treatment}

Fludarabine, cyclophosphamide, and rituximab (FCR) is currently the standard for first-line treatment of fit patients. This was established by the German CLL8 phase III study, which randomized 408 untreated fit patients (CIRS $\leq 6$, creatinine clearance $\geq 70 \mathrm{ml} / \mathrm{min}$ ) between FC and FCR regimens. Therapy with FCR resulted in a significantly higher CR rate (44\% vs. $22 \%, p<0.0001)$, longer progression-free survival (PFS; $65 \%$ vs. $45 \%$ without progression at 3 years, $p<0.0001)$ and also longer overall survival (OS, $87 \%$ vs. $83 \%$ alive at 3 years, $p=0.01)$. There was a significant increase in severe (grade III/IV) neutropenia (34\% vs. $21 \%, p<0.0001$ ) but without significantly elevated occurrence of infections. Patients with del 17p and/or p53 mutation have typically lower response rates to FCR, but this regimen can still be used for first-line treatment outside clinical trials, as monotherapy with alemtuzumab in the same setting did not yield better efficacy [35] and the combination of alemtuzumab and high-dose corticosteroids, the most effective approach for patients with defective p53 so far, has been reported only in a small number of untreated patients $(n=17)$ [36].

Elderly/comorbid patients require a different approach, as the number and severity of comorbid conditions contribute to inferior tolerance of chemotherapy [33]. In particular, full-dose fludarabine regimens in elderly patients may result in unacceptable toxicity $[37,38]$.

Chlorambucil (CLB) was introduced into CLL therapy in the 1950s [39] but could be considered the backbone of treatment in frail patients until recently as no other regimens proved to be superior. Several dosing schedules of chlorambucil are possible, e.g.: 1) $0.4-0.8 \mathrm{mg} / \mathrm{kg}$ administered every 2 weeks (used by the German CLL Study Group, GCLLSG) [35], 2) $10 \mathrm{mg} / \mathrm{m}^{2}$ days $1-7$ repeated every 28 days [6]. Overall response rate (ORR) and progression-free survival (PFS) ranged from $37 \%$ to $72 \%$ and 9 to 20 months, depending on the patient population. Complete responses are infrequent with CLB monotherapy. The German CLL5 study showed that although fludarabine induced significantly more overall responses (ORR) and complete remissions (CR) than CLB in untreated patients $\geq 65$ years in (ORR: $72 \%$ vs. $51 \%, p=0.003$; CR: $7 \%$ vs. $0 \%, p=0.011$ ), it did not translate into longer progression-free (median: 19vs. 18 months, $p=0.7$ ) or overall survival (median: 46 vs. 64 months, $p=0.15$ ) [40]. Recently, two randomized studies published in abstract form showed for the first time significant improvement over CLB monotherapy. The German CLL11 study randomized 589 untreated patients with significant comorbidities (cumulative CIRS score $\geq 7$ and/or creatinine clearance $<70 \mathrm{ml} / \mathrm{min}$ ) in $1: 2: 2$ fashion between 
CLB monotherapy $(0.5 \mathrm{mg} / \mathrm{kg}$ days 1 and 15 , for a maximum of 6 cycles), CLB + rituximab (R-CLB, $375 \mathrm{mg} / \mathrm{m}^{2}$ i.v. day 1 , cycle $1 ; 500 \mathrm{mg} / \mathrm{m}^{2}$ day 1 in cycles 2-6), and CLB + obinutuzumab (GA-101), a novel humanized type II glycoengineered antiCD20 antibody with enhanced direct cell killing and antibody-dependent cytotoxicity (G-CLB, $100 \mathrm{mg}$ i.v. day $1,900 \mathrm{mg}$ i.v. day 2, $1000 \mathrm{mg}$ i.v. days 8 and 15 of cycle $1,1000 \mathrm{mg}$ i.v. day 1 in cycles 2-6). Both combination regimens proved significantly superior to CLB monotherapy in terms of CR rate (R-CLB: $8 \%$; G-CLB: $22 \%$, CLB: $0 \%$ ) and PFS (R-CLB: 15.7 months; G-CLB: 23 months; CLB: 10.9 months, $p<0.0001)$. In addition, patients treated with G-CLB had significantly longer overall survival in comparison to CLB alone (median OS not reached in either group, death rate $9 \%$ vs. $20 \%$, $p=0.002$ ). Differences in CR rate and PFS were also significantly better with G-CLB vs. R-CLB. Obinutuzumab caused more severe infusion-related toxicity than rituximab ( $21 \%$ vs. $4 \%$ ) and more frequent severe neutropenia than rituximab or CLB ( $34 \%$ vs. $25 \%$ vs. $15 \%$ ), but this did not translate into an increased rate of severe infections ( $6 \%$ vs. $8 \%$ vs. $11 \%$ ) [41]. Based on these results, obinutuzumab was approved for first-line treatment of CLL in comorbid patients. Combination of CLB and ofatumumab, a fully human anti-CD20 antibody with enhanced complement-dependent cytotoxicity, was compared against CLB monotherapy in another large phase III randomized study. A total of 447 untreated CLL patients older than 65 years were randomized between CLB $\left(10 \mathrm{mg} / \mathrm{m}^{2}\right.$ days 1-7 repeated every 28 days for a maximum of 12 cycles) and CLB + ofatumumab (O-CLB, $300 \mathrm{mg}$ i.v. day $1,1000 \mathrm{mg}$ day 8 cycle $1,1000 \mathrm{mg}$ i.v. day 1 , in cycles 2-12, cycles repeated every 28 days). The O-CLB combination achieved significantly more ORR/CR (82/14\% vs. 69/1\%, $p<0.001)$ as well as longer PFS (22.4 months vs. 13.1 months, $p<0.001)$ with no unexpected toxicity. Serious infusion-related reactions occurred in 10\% [42]. Taken together, these two studies indicate that combination of CLB and anti-CD20 monoclonal antibody is becoming a new standard of care in untreated comorbid CLL patients.

Bendamustine is a unique cytostatic agent with combined properties of an alkylating agent and purine analog, originally developed in the 1960 s in the former East Germany. An international phase III study randomized 305 untreated CLL patients between bendamustine $\left(100 \mathrm{mg} / \mathrm{m}^{2}\right.$ i.v. days $1-2$ repeated every 28 days) and chlorambucil $(0.8 \mathrm{mg} / \mathrm{kg}$ days 1 and 15 , repeated every 28 days). Bendamustine showed significantly higher OR/CR (68/30\% vs. $39 / 2 \%)$ as well as PFS (21.7 vs. 9.3 months) [6]. These results led to approval of bendamustine for the first-line treatment of CLL patients ineligible for FCR. Bendamustine has also been successfully combined with rituximab (BR regimen) in a phase II trial by GCLLSG. A total of 117 patients with median age 64 years $(26 \%$ older than 70) received bendamustine $90 \mathrm{mg} / \mathrm{m}^{2}$ i.v. days $1-2$, repeated every 4 weeks plus rituximab in a standard CLL dose for up to 6 cycles. ORR/CR rates were $88 / 23 \%$; median event-free survival was 27 months; severe neutropenia and infections developed in $20 \%$ and $8 \%$ only [43]. BR is currently being compared with FCR in untreated fit patients within the German phase III randomized study CLL10.

Dose-reduced fludarabine regimens represent a logical approach with the goal of reduced toxicity and preserved efficacy. Several single-center studies reported promising efficacy and manageable toxicity of low-dose fludarabine-based combinations [44]. The low-dose FCR regimen (fludarabine $12 \mathrm{mg} / \mathrm{m}^{2}$ i.v. or $20 \mathrm{mg} / \mathrm{m}^{2}$ orally days $1-3$, cyclophosphamide $150 \mathrm{mg} / \mathrm{m}^{2}$ i.v./orally days $1-3$, rituximab standard CLL dose, repeated every 28 days) used by the Czech CLL Study Group reported very good efficacy in elderly/comorbid CLL patients in treatment of first-line ( $n=102$; ORR: 79\%; median PFS: 20 months) as well as relapsed/ refractory disease ( $n=97$; ORR: $64 \%$; median PFS: 15 months). Toxicity was acceptable (severe neutropenia, 57 and 49\%; severe infections, 14 and $18 \%$ of patients) [45].

\section{Treatment of relapse}

Identically to first-line treatment, relapsed CLL should only be treated when indications for treatment are fulfilled (Table V). Patients with relapsed $C L L$ may be retreated with the same regimen used in the previous line of treatment if a therapeutic response was achieved and the duration of response exceeded 12 months for monotherapy protocols or 24 months for fludarabine combinations (e.g., FC, FCR) [13]. FCR is the most suitable second-line regimen for patients who are not pretreated with rituximab or fludarabine combinations, as the randomized REACH study showed a higher CR rate (24 vs. $13 \%, p<0.001)$ and longer PFS (30.6 vs. 20.6 months, $p<0.001)$ in comparison to FC, without significantly increased infection frequency [5].

\section{Refractory chronic lymphocytic leukemia}

Treatment of refractory CLL represents one of the most challenging situations in hematological oncology. Despite impressive efficacy of fludarabine-based chemoimmunotherapy, $5-10 \%$ of patients will not respond to first-line treatment and others will become fludarabine-refractory in subsequent lines of therapy.

The humanized monoclonal anti-CD52 antibody alemtuzumab is indicated in fludarabine-re- 
Table VII. Most frequently used therapeutic regimens for chronic lymphocytic leukemia (CLL)

\begin{tabular}{|c|c|}
\hline Protocol & Schedule \\
\hline Chlorambucil & $\begin{array}{l}10 \mathrm{mg} / \mathrm{m}^{2} \text { orally on days } 1-7 \text {, repeated every } 4 \text { weeks } \\
0.4-0.8 \mathrm{mg} / \mathrm{kg} \text { orally on day } 1 \text {, repeated every } 2 \text { weeks }\end{array}$ \\
\hline FCR & $\begin{array}{l}\text { F: } 40 \mathrm{mg} / \mathrm{m}^{2} \text { orally or } 25 \mathrm{mg} / \mathrm{m}^{2} \text { i.v. on days } 1-3, \mathrm{C}: 250 \mathrm{mg} / \mathrm{m}^{2} \text { orally } / \text { i.v. on days } 1-3 \text {, } \\
\text { R: } 500 \mathrm{mg} / \mathrm{m}^{2}\left(375 \mathrm{mg} / \mathrm{m}^{2} \text { in } 1^{\text {st }} \text { cycle) } \text { i.v. on day } 1 \text {, repeated every } 4 \text { weeks }\right.\end{array}$ \\
\hline Bendamustine & $100 \mathrm{mg} / \mathrm{m}^{2}$ i.v. on days $1-2$, repeated every 4 weeks \\
\hline $\mathrm{BR}$ - untreated CLL & $\begin{array}{l}\text { B: } 90 \mathrm{mg} / \mathrm{m}^{2} \text { i.v. on days } 1-2, \mathrm{R}: 500 \mathrm{mg} / \mathrm{m}^{2}\left(375 \mathrm{mg} / \mathrm{m}^{2} \text { in } 1^{\text {st }} \text { cycle }\right) \text { i.v. on day } 1 \text {, } \\
\text { repeated every } 4 \text { weeks }\end{array}$ \\
\hline $\begin{array}{l}\mathrm{BR}-\text { relapsed/ } \\
\text { refractory } \mathrm{CLL}\end{array}$ & $\begin{array}{l}\text { B: } 70 \mathrm{mg} / \mathrm{m}^{2} \text { i.v. on days } 1-2, \mathrm{R}: 500 \mathrm{mg} / \mathrm{m}^{2}\left(375 \mathrm{mg} / \mathrm{m}^{2} \text { in } 1^{\text {st }} \text { cycle }\right) \text { i.v. on day } 1 \text {, } \\
\text { repeated every } 4 \text { weeks }\end{array}$ \\
\hline Alemtuzumab & $30 \mathrm{mg}$ i.v./subcutaneously $3 \times$ weekly for 12 weeks (dose escalation 3-10-30 mg in $1^{\text {st }}$ week) \\
\hline Ofatumumab & $\begin{array}{l}300 \mathrm{mg} \text { i.v. on day } 1 \text {, then } 7 \text { infusions of } 2000 \mathrm{mg} \text { i.v. weekly, } \\
\text { then } 4 \text { infusions of } 2000 \mathrm{mg} \text { i.v. monthly }\end{array}$ \\
\hline
\end{tabular}

$F$-fludarabine, $C$-cyclophosphamide, $R$ - rituximab, $B$ - bendamustine.

fractory patients. Overall response rate can be expected between $30 \%$ and $40 \%$, but complete responses are rare and response duration usually does not exceed 12 months [7, 46]. In addition, alemtuzumab causes severe and long-lasting immune suppression due to depletion of $B$ and T cells; therefore, combined antimicrobial prophylaxis and cytomegalovirus monitoring are compulsory [47] and the risk : benefit ratio must be carefully assessed. Double refractory patients (i.e., refractory to fludarabine and alemtuzumab) or fludarabine-refractory with bulky lymphadenopathy (thus not good candidates for alemtuzumab) have an extremely unfavorable prognosis [48].

The German CLL Study Group reported results of bendamustine + rituximab (BR) combination in 78 relapsed/refractory patients (median age: 66.5 years; median previous treatment lines: 2 ; $28 \%$ fludarabine-refractory; $18 \%$ with $17 p$ deletion). The bendamustine dose was $70 \mathrm{mg} / \mathrm{m}^{2}$ i.v. days $1-2$, repeated every 4 weeks. The ORR/CR rate was $59 / 9 \%$, including $46 \%$ in fludarabine-refractory but only $7 \%$ in del $17 \mathrm{p}$. Median PFS was 15 months; severe neutropenia and infections developed in $23 \%$ and $13 \%$ only [49].

Ofatumumab is the only agent approved for the treatment of double-refractory CLL owing to results of a large international phase II trial which treated 206 heavily pretreated patients (double refractory, $n=95$; bulky fludarabine refractory, $n=11$, median age was 64 years, median previous therapies, 5 and 4). Treatment consisted of 8 weekly i.v. infusions $(1 \times 300 \mathrm{mg}+7 \times 2000 \mathrm{mg})$ followed by four monthly infusions of $2000 \mathrm{mg}$. ORR was $51 \%$ and $44 \%$, median PFS 5.5 months and median OS 14.2 and 17.4 months. Infusion-related side effects were seen in $63 \%$ of patients, but $95 \%$ of these were grade I-II. Severe infections developed in $24 \%$ of patients [8].

Combination of high-dose corticosteroids with monoclonal antibodies emerged as a promising option for relapsed/refractory CLL. Rituximab with high-dose methylprednisolone (HDMP, $1 \mathrm{~g} / \mathrm{m}^{2}$ i.v. days $1-5$ ) was effective but relatively toxic (steroid diabetes, fluid retention, severe infections up to $50 \%$, early deaths on treatment) in several small studies [9, 50-54]. Following promising results of a substantially lower dose of dexamethasone (40 mg orally days $1-4$ combined with rituximab) [52], a two-center retrospective study reported results in 54 patients with relapsed/refractory CLL ( $82 \%$ pretreated with fludarabine and $29 \%$ with alemtuzumab). Dexamethasone was given $40 \mathrm{mg}$ orally on days 1-4 and 10-13; rituximab was administered on day 1 and cycles repeated every 21 days $(n=25)$ or weekly with cycles repeated every 28 days $(n=29)$. ORR/CR was $71 / 4$ and 62/21\%; median PFS was 6.9 and 6.9 months. Three patients proceeded successfully to nonmyeloablative allogeneic stem cell transplantation. Serious infections occurred in $32 \%$ of patients [55]. Table VII summarizes the most frequently used regimens for treatment of CLL.

\section{Allogeneic stem cell transplantation}

Allogeneic stem cell transplantation (alloSCT) currently represents the only potentially curative treatment option in patients with CLL. Reduced intensity conditioning (RIC) using lower doses of cytotoxic agents is nowadays almost exclusively performed because of significantly lower non-relapse mortality than myeloablative conditioning; the graft-versus-leukemia (GVL) effect is very well characterized in CLL. Acute and chronic graft-versus-host disease remains a significant problem [10, 11]. Autologous transplantation has been abandoned in CLL as it did not convey any advantage over chemoimmunotherapy [56]. It is essential that every patient with a highly unfavorable disease course should be assessed regarding the possibility of alloSCT. Indications for alloSCT 
Table VIII. European Research Initiative for Chronic lymphocytic leukemia (ERIC) indication criteria for allogeneic transplantation in chronic lymphocytic leukemia (CLL)

\begin{tabular}{|l|}
\hline $\begin{array}{l}\text { Allogeneic stem cell transplantation is a reasonable } \\
\text { option for poor risk CLL }\end{array}$ \\
\hline 1. Purine analog-refractory CLL \\
\hline $\begin{array}{l}\text { 2. Short response duration to previous therapy: } \\
\leq 12 \text { months for purine analog monotherapy } \\
\leq 24 \text { months for combination therapy (e.g., FCR) }\end{array}$ \\
$\begin{array}{l}\text { 3. Deletion/mutation of p53 with indication for } \\
\text { treatment }\end{array}$ \\
\hline
\end{tabular}

according to European Blood and Marrow Transplantation (EBMT) are listed in Table VIII. Ideally, alloSCT in CLL patients should be performed within prospective clinical trials [57].

\section{Minimal residual disease}

A seminal study using the monoclonal antiCD52 antibody alemtuzumab demonstrated that patients who achieved eradication of minimal residual disease (i.e., negativity of highly sensitive methods such as multicolor flow cytometry or PCR with patient-specific primers) had not only significantly longer PFS but also overall survival (OS) [13]. These results were recently corroborated by the results of the randomized CLL-8 study (FCR vs. FC in untreated fit patients) [4]. The study identified minimal residual disease (MRD) measured by four-color flow cytometry as an independent predictor of PFS and OS. Patients who achieved $M R D \leq 10^{-4}$ had the best outcome irrespective of treatment arm [58]. While MRD in CLL is a very powerful predictive factor and MRD negativity will probably be used in clinical trials as a surrogate marker for PFS, MRD is not yet recognized as a compulsory parameter in routine practice.

\section{Novel agents}

Recent years have witnessed an explosion of clinical studies using novel targeted drugs in
CLL. The two most promising agents appear to be ibrutinib, an inhibitor of Bruton tyrosine kinase, and idelalisib, an inhibitor of phosphatidyl-3-inositol kinase (PI3K) delta. Both of these agents target downstream B-cell receptor signaling pathways, are orally available and are designed for prolonged administration until CLL progression or unacceptable toxicity. Ibrutinib achieved excellent results in a phase $1 \mathrm{~b} / 2$ trial [59] and subsequently demonstrated superiority over ofatumumab in terms of better ORR, PFS and OS in a randomized trial in heavily pretreated CLL patients [60]. Idelalisib in combination with rituximab showed superior ORR, PFS as well as OS over rituximab monotherapy in relapsed/refractory patients deemed unfit for chemotherapy [61]. These studies resulted in recent approval of ibrutinib and idelalisib for the treatment of CLL. Further agents in advanced phases of clinical trials include the bcl-2 inhibitor venetoclax (GDC-0199, ABT-199), the immunomodulating agent lenalidomide, the PI3K inhibitor IPI-145, and modified autologous T-cells with chimeric antiCD19 antigen (CARs) (Table IX) [62].

\section{Conclusions}

We are entering a completely new era in prognostication and treatment of CLL. While diagnostic criteria will probably not change very soon, further refinement of individual patient prognosis is very likely. The indication for treatment is still based solely on clinical activity of CLL. Currently running clinical trials will provide information whether early treatment of patients with unfavorable prognosis confers clinical benefit. Chemoimmunotherapy can be currently regarded as the gold standard for fit as well as comorbid patients. Novel targeted agents have promising activity in relapsed/refractory disease where prognosis is still poor. Therefore, achievement of the most important therapeutic goals - prolongation of overall survival and improvement in quality of life - can be expected in a growing number of CLL patients in the near future.

Table IX. Novel agents for the treatment of chronic lymphocytic leukemia (CLL)

\begin{tabular}{|lll|}
\hline Agent & Mechanism of action & Phase of development \\
\hline Obinutuzumab (GA-101) & Glycoengineered type II anti-CD20 antibody & Approved; phase III \\
\hline Ibrutinib (PCl-32765) & Bruton tyrosine kinase inhibition & Approved; phase III \\
\hline Idelalisib (GS-1101) & Phosphatidylinositol-3-kinase delta inhibition & Approved; phase III \\
\hline Lenalidomide & Complex- microenvironment & Phase III \\
\hline Venetoclax (GDC-0199, ABT-199) & Bcl-2 inhibition & Phase III \\
\hline IPI-145 & Phosphatidylinositol-3-kinase inhibition & Phase II/III \\
\hline CAR T-cells & T-lymphocytes with chimeric anti CD19 receptor & Phase II \\
\hline
\end{tabular}




\section{Acknowledgments}

Supported by grant IGAMHCZNT13412-4/2012, by MH CZ - DRO (UHHK, 00179906) and by program PRVOUK P37/08.

\section{Conflict of interest}

LS: Roche, Janssen, GlaxoSmithKline, Sanofi, Gilead, and Bayer Schering Pharma - travel grants, honoraria, consultations, advisory board. MŠ: Roche - travel grants, honoraria.

\section{References}

1. Dores GM, Anderson WF, Curtis RE, et al. Chronic lymphocytic leukaemia and small lymphocytic lymphoma: overview of the descriptive epidemiology. Br J Haematol 2007; 139: 809-19.

2. Hallek M. Chronic lymphocytic leukemia: 2013 update on diagnosis, risk stratification and treatment. Am J Hematol 2013; 88: 803-16.

3. Rosenquist R, Cortese D, Bhoi S, Mansouri L, Gunnarsson R. Prognostic markers and their clinical applicability in chronic lymphocytic leukemia: where do we stand? Leuk Lymphoma 2013; 54: 2351-64.

4. Hallek M, Fischer K, Fingerle-Rowson G, et al. Addition of rituximab to fludarabine and cyclophosphamide in patients with chronic lymphocytic leukaemia: a randomised, open-label, phase 3 trial. Lancet 2010; 376: 1164-74.

5. Robak T, Dmoszynska A, Solal-Celigny P, et al. Rituximab plus fludarabine and cyclophosphamide prolongs progression-free survival compared with fludarabine and cyclophosphamide alone in previously treated chronic lymphocytic leukemia. J Clin Oncol 2010; 28: 1756-65.

6. Knauf WU, Lissichkov T, Aldaoud A, et al. Phase III randomized study of bendamustine compared with chlorambucil in previously untreated patients with chronic lymphocytic leukemia. J Clin Oncol 2009; 27: 4378-84.

7. Keating MJ, Flinn I, Jain V, et al. Therapeutic role of alemtuzumab (Campath-1H) in patients who have failed fludarabine: results of a large international study. Blood 2002; 99: 3554-61.

8. Wierda WG, Kipps TJ, Mayer J, et al. Ofatumumab as single-agent CD20 immunotherapy in fludarabine-refractory chronic lymphocytic leukemia. J Clin Oncol 2010; 28: 1749-55.

9. Smolej L. The role of high-dose corticosteroids in the treatment of chronic lymphocytic leukemia. Expert Opin Investig Drugs 2012; 21: 1009-17.

10. Dreger $P$. The evolving role of stem cell transplantation in chronic lymphocytic leukemia. Hematol Oncol Clin North Am 2013; 27: 355-69.

11. Bottcher S, Ritgen M, Dreger P. Allogeneic stem cell transplantation for chronic lymphocytic leukemia: lessons to be learned from minimal residual disease studies. Blood Rev 2011; 25: 91-6.

12. Isfort S, Cramer P, Hallek M. Novel and emerging drugs for chronic lymphocytic leukemia. Curr Cancer Drug Targets 2012; 12: 471-83.

13. Hallek M, Cheson BD, Catovsky D, et al. Guidelines for the diagnosis and treatment of chronic lymphocytic leukemia: a report from the International Workshop on Chronic Lymphocytic Leukemia updating the National Cancer Institute-Working Group 1996 guidelines. Blood 2008; 111: 5446-56.
14. Moreau EJ, Matutes E, A'Hern RP, et al. Improvement of the chronic lymphocytic leukemia scoring system with the monoclonal antibody SN8 (CD79b). Am J Clin Pathol 1997; 108: 378-82.

15. Muntanola A, Bosch F, Arguis P, et al. Abdominal computed tomography predicts progression in patients with Rai stage 0 chronic lymphocytic leukemia. J Clin Oncol 2007; 25: 1576-80.

16. Gentile M, Cutrona G, Fabris S, et al. Total body computed tomography scan in the initial work-up of Binet stage A chronic lymphocytic leukemia patients: results of the prospective, multicenter O-CLL1-GISL study. Am J Hematol 2013; 88: 539-44.

17. Rai KR, Sawitsky A, Cronkite EP, Chanana AD, Levy RN, Pasternack BS. Clinical staging of chronic lymphocytic leukemia. Blood 1975; 46: 219-34.

18. Binet JL, Auquier A, Dighiero G, et al. A new prognostic classification of chronic lymphocytic leukemia derived from a multivariate survival analysis. Cancer 1981; 48: 198-206.

19. Dohner H, Stilgenbauer S, Benner A, et al. Genomic aberrations and survival in chronic lymphocytic leukemia. N Engl J Med 2000; 343: 1910-6.

20. Trbusek M, Malcikova J. TP53 aberrations in chronic lymphocytic leukemia. Adv Exp Med Biol 2013; 792: 109-31.

21. Schnaiter A, Stilgenbauer S. 17p deletion in chronic lymphocytic leukemia: risk stratification and therapeutic approach. Hematol Oncol Clin North Am 2013; 27: 289-301.

22. Pospisilova S, Gonzalez D, Malcikova J, et al. ERIC recommendations on TP53 mutation analysis in chronic lymphocytic leukemia. Leukemia 2012; 26: 1458-61.

23. Zenz T, Habe S, Denzel T, et al. Detailed analysis of $\mathrm{p} 53$ pathway defects in fludarabine-refractory chronic lymphocytic leukemia (CLL): dissecting the contribution of 17p deletion, TP53 mutation, p53-p21 dysfunction, and miR34a in a prospective clinical trial. Blood 2009; 114: 2589-97.

24. Shanafelt TD, Witzig TE, Fink SR, et al. Prospective evaluation of clonal evolution during long-term follow-up of patients with untreated early-stage chronic lymphocytic leukemia. J Clin Oncol 2006; 24: 4634-41.

25. Rossi D, Fangazio M, Rasi S, et al. Disruption of BIRC3 associates with fludarabine chemorefractoriness in TP53 wild-type chronic lymphocytic leukemia. Blood 2012; 119: 2854-62.

26. Rossi D, Rasi S, Fabbri G, et al. Mutations of NOTCH1 are an independent predictor of survival in chronic lymphocytic leukemia. Blood 2012; 119: 521-9.

27. Quesada V, Ramsay AJ, Lopez-Otin C. Chronic lymphocytic leukemia with SF3B1 mutation. N Engl J Med 2012; 366: 2530.

28. Eichhorst BF, Fischer K, Fink AM, et al. Limited clinical relevance of imaging techniques in the follow-up of patients with advanced chronic lymphocytic leukemia: results of a meta-analysis. Blood 2011; 117: 1817-21.

29. Diehl LF, Karnell LH, Menck HR. The American College of Surgeons Commission on Cancer and the American Cancer Society. The National Cancer Data Base report on age, gender, treatment, and outcomes of patients with chronic lymphocytic leukemia. Cancer 1999; 86: 2684-92.

30. Molica S, Levato D. What is changing in the natural history of chronic lymphocytic leukemia? Haematologica 2001; 86: 8-12.

31. Panovska A, Doubek M, Brychtova Y, Mayer J. Chronic lymphocytic leukemia and focusing on epidemiology and management in everyday hematologic practice: re- 
cent data from the Czech Leukemia Study Group for Life (CELL). Clin Lymphoma Myeloma Leuk 2010; 10: 297-300.

32. Shenoy PJ, Malik N, Sinha R, et al. Racial differences in the presentation and outcomes of chronic lymphocytic leukemia and variants in the United States. Clin Lymphoma Myeloma Leuk 2011; 11: 498-506.

33. Eichhorst B, Goede V, Hallek M. Treatment of elderly patients with chronic lymphocytic leukemia. Leuk Lymphoma 2009; 50: 171-8.

34. Cockcroft DW, Gault MH. Prediction of creatinine clearance from serum creatinine. Nephron 1976; 16: 31-41.

35. Hillmen P, Skotnicki AB, Robak T, et al. Alemtuzumab compared with chlorambucil as first-line therapy for chronic lymphocytic leukemia. J Clin Oncol 2007; 25: 5616-23.

36. Pettitt AR, Jackson R, Carruthers $S$, et al. Alemtuzumab in combination with methylprednisolone is a highly effective induction regimen for patients with chronic lymphocytic leukemia and deletion of TP53: final results of the national cancer research institute CLL206 trial. J Clin Oncol 2012; 30: 1647-55.

37. Shvidel L, Shtalrid M, Bairey O, et al. Conventional dose fludarabine-based regimens are effective but have excessive toxicity in elderly patients with refractory chronic lymphocytic leukemia. Leuk Lymphoma 2003; 44: 1947-50.

38. Ferrajoli A, O'Brien S, Wierda W et al. Treatment of patients with CLL 70 years old and older: a single center experience of 142 patients. Leuk Lymphoma 2005; 46 (Suppl 1): S86 (abstract P95).

39. Altman SJ, Haut A, Cartwright GE, Wintrobe MM. Early experience with $\mathrm{p}$-(N, N-di-2-chloroethyl)-aminophenylbutyric acid (CB 1348), a new chemotherapeutic agent effective in the treatment of chronic lymphocytic leukemia. Cancer 1956; 9: 512-7.

40. Eichhorst BF, Busch R, Stilgenbauer S, et al. First-line therapy with fludarabine compared with chlorambucil does not result in a major benefit for elderly patients with advanced chronic lymphocytic leukemia. Blood 2009; 114: 3382-91.

41. Goede V, Fischer K, Busch R, et al. Obinutuzumab plus chlorambucil in patients with CLL and coexisting conditions. N Engl J Med 2014; 370: 1101-10.

42. Hillmen P, Robat T, Janssens A et al. Ofatumumab + chlorambucil versus chlorambucil alone in patients with untreated chronic lymphocytic leukemia $(C L L)$ : results of the phase III study complement 1 (OMB110911). ASH Annual Meeting abstracts. Blood 2013; 122: 528.

43. Fischer K, Cramer P, Busch R, et al. Bendamustine in combination with rituximab for previously untreated patients with chronic lymphocytic leukemia: a multicenter phase II trial of the German Chronic Lymphocytic Leukemia Study Group. J Clin Oncol 2012; 30: 3209-16.

44. Smolej L. Therapy of elderly/comorbid patients with chronic lymphocytic leukemia. Curr Pharm Des 2012; 18: 3399-405.

45. Smolej L, Brychtová Y, Cmunt E, et al. Low-dose FCR in elderly/comorbid patients with chronic lymphocytic leukemia/small lymphocytic lymphoma: Predictors of Progression-Free Survival. Project Q-lite by Czech CLL Study Group. Haematologica 2013; 98 (Suppl. 1): 41 (abstract P096).

46. Stilgenbauer S, Zenz T, Winkler D, et al. Subcutaneous alemtuzumab in fludarabine-refractory chronic lymphocytic leukemia: clinical results and prognostic marker analyses from the CLL2H study of the German Chronic Lymphocytic Leukemia Study Group. J Clin Oncol 2009; 27: 3994-4001.
47. Osterborg A, Foa R, Bezares RF, et al. Management guidelines for the use of alemtuzumab in chronic lymphocytic leukemia. Leukemia 2009; 23: 1980-8.

48. Tam CS, O’Brien S, Lerner S, et al. The natural history of fludarabine-refractory chronic lymphocytic leukemia patients who fail alemtuzumab or have bulky lymphadenopathy. Leuk Lymphoma 2007; 48: 1931-9.

49. Fischer K, Cramer P, Busch R, et al. Bendamustine combined with rituximab in patients with relapsed and/or refractory chronic lymphocytic leukemia: a multicenter phase II trial of the German Chronic Lymphocytic Leukemia Study Group. J Clin Oncol 2011; 29: 3559-66.

50. Bowen DA, Call TG, Jenkins GD, et al. Methylprednisolone-rituximab is an effective salvage therapy for patients with relapsed chronic lymphocytic leukemia including those with unfavorable cytogenetic features. Leuk Lymphoma 2007; 48: 2412-7.

51. Dungarwalla M, Evans SO, Riley U, Catovsky D, Dearden CE, Matutes E. High dose methylprednisolone and rituximab is an effective therapy in advanced refractory chronic lymphocytic leukemia resistant to fludarabine therapy. Haematologica 2008; 93: 475-6.

52. Castro JE, Sandoval-Sus JD, Bole J, Rassenti L, Kipps TJ. Rituximab in combination with high-dose methylprednisolone for the treatment of fludarabine refractory high-risk chronic lymphocytic leukemia. Leukemia 2008; 22: 2048-53.

53. Pileckyte R, Jurgutis $M$, Valceckiene V, et al. Dose-dense high-dose methylprednisolone and rituximab in the treatment of relapsed or refractory high-risk chronic lym phocytic leukemia. Leuk Lymphoma 2011; 52: 1055-65.

54. Quinn JP, Mohamedbhai S, Chipperfield K, Treacy M, D'Sa S, Nathwani AC. Efficacy of rituximab in combination with steroids in refractory chronic lymphocytic leukemia. Leuk Lymphoma 2008; 49: 1995-8.

55. Smolej L, Doubek M, Panovska A, et al. Rituximab in combination with high-dose dexamethasone for the treatment of relapsed/refractory chronic lymphocytic leukemia. Leuk Res 2012; 36: 1278-82.

56. Michallet M, Dreger P, Sutton L, et al. Autologous hematopoietic stem cell transplantation in chronic lymphocytic leukemia: results of European intergroup random ized trial comparing autografting versus observation. Blood 2011; 117: 1516-21.

57. Dreger P, Schetelig J, Andersen N, et al. Managing highrisk CLL during transition to a new treatment era: stem cell transplantation or novel agents? Blood 2014; 124 3841-9.

58. Bottcher S, Ritgen M, Fischer K, et al. Minimal residual disease quantification is an independent predictor of progression-free and overall survival in chronic lymphocytic leukemia: a multivariate analysis from the randomized GCLLSG CLL8 trial. J Clin Oncol 2012; 30: 980-8.

59. Byrd JC, Furman RR, Coutre SE, et al. Targeting BTK with ibrutinib in relapsed chronic lymphocytic leukemia. N Engl J Med 2013; 369: 32-42.

60. Byrd JC, Brown JR, O’Brien S, et al. Ibrutinib versus ofatumumab in previously treated chronic lymphoid leukemia. N Engl J Med 2014; 371: 213-23.

61. Furman RR, Sharman JP, Coutre SE, et al. Idelalisib and rituximab in relapsed chronic lymphocytic leukemia. N Engl J Med 2014; 370: 997-1007.

62. http://clinicaltrials.gov/ct2/results?term=chronic+lym phocytic+leukemia\&recr=Open\&no_unk $=Y \&$ type $=$ In tr\&phase $=12 \& p g=1$. Accessed on October 8th, 2014. 